\title{
A Short Film That Addresses Substance Use Disorders in Rural Communities and Strategies in Prevention and Treatment of Addiction
}

Sarah R. Poteracki

srp0037@mix.wvu.edu

Follow this and additional works at: https://researchrepository.wvu.edu/etd

Part of the Community-Based Research Commons, Community Health Commons, Health Communication Commons, Psychiatric and Mental Health Commons, and the Substance Abuse and Addiction Commons

\section{Recommended Citation}

Poteracki, Sarah R., "A Short Film That Addresses Substance Use Disorders in Rural Communities and Strategies in Prevention and Treatment of Addiction" (2021). Graduate Theses, Dissertations, and Problem Reports. 8346.

https://researchrepository.wvu.edu/etd/8346

This Thesis is protected by copyright and/or related rights. It has been brought to you by the The Research Repository @ WVU with permission from the rights-holder(s). You are free to use this Thesis in any way that is permitted by the copyright and related rights legislation that applies to your use. For other uses you must obtain permission from the rights-holder(s) directly, unless additional rights are indicated by a Creative Commons license in the record and/ or on the work itself. This Thesis has been accepted for inclusion in WVU Graduate Theses, Dissertations, and Problem Reports collection by an authorized administrator of The Research Repository @ WVU. For more information, please contact researchrepository@mail.wvu.edu. 


\title{
A SHORT FILM THAT ADDRESSES SUBSTANCE USE DISORDERS IN RURAL COMMUNITIES AND STRATEGIES IN PREVENTION AND TREATMENT OF ADDICTION
}

\author{
Sarah Poteracki \\ A professional project submitted \\ to the Reed College of Media \\ at West Virginia University \\ Master of Science in \\ Journalism \\ Lois Raimondo, M.A., Chair \\ Gina Martino Dahlia, M.S.J. \\ John Temple, M.F.A. \\ Judith Feinberg, M.D. \\ Department of Media
}

in partial fulfillment of the requirements for the degree of

Morgantown, West Virginia

2021

Keywords: substance use disorder, research collaboration, stigma

Copyright 2021 Sarah Poteracki 


\section{ABSTRACT \\ A SHORT FILM THAT ADDRESSES SUBSTANCE USE DISORDERS \\ IN RURAL COMMUNITIES AND STRATEGIES IN \\ PREVENTION AND TREATMENT OF ADDICTION}

\section{Sarah Poteracki}

This research paper and accompanying video (link to the short film is here:

https://drive.google.com/drive/folders/1etDnUmEvkOds8J0EKnq1gnFO79-GggjY) offer insight into the current state of research collaboration surrounding substance use disorders in West Virginia. This professional project explores the importance of collaboration both in a research and clinical setting and in the social realm. The film was shown at the 2 nd annual meeting for the Appalachian Node of the National Institute on Drug Abuse Clinical Trials Network on February 25, 2021. I interviewed 14 researchers and experts from a diverse range of disciplines who shared insights and strategies in the prevention and treatment of addiction in rural communities. The drug overdose death rate in rural areas is higher than in urban areas. This film explores how different strategies can be applied in rural communities to fight against drugs and substance abuse through prevention, treatment and rehabilitation. 


\section{Table of Contents}

Introduction.................................................................. 1

The Project............................................................. 3

Project Description................................................ 3

Implications..................................................... 3

The Process................................................................... 3

I. Establishing Research Statement and Methodology.................... 4

II. Identifying Subject Pool.............................................. 4

III. Scheduling...................................................... 7

IV. Conducting Interviews........................................... 8

V. Organizing Footage and Transcripts................................ 8

VI. Video Production...................................................... 9

VII. Meeting Presentation......................................... 10

Conclusions.............................................................. 10

I. Technical Aspects.............................................. 10

II. Insights..................................................... 11

III. Suggestions for Future Research................................ 14

Literature Review........................................................ 15

Substance Use Disorder Research Collaboration in West Virginia.............. 15

NIDA CTN Appalachian Node..................................... 17

Stigma and Overdose-Related Compassion Fatigue.......................... 18

Filmic Treatments............................................... 23

Works Cited............................................................. 25 


\section{Introduction}

For my professional project work, I interviewed 13 West Virginia University researchers and clinicians as well as one community partner focused on issues of substance use disorder in the Appalachian region. Their paths to this area of research have varied greatly - from spatial epidemiology to obstetrics to neuropsychology - but today each and every one of them have refocused their energy on the many issues - biological, psychological, social and more surrounding substance use disorder. The video assembled from their Zoom footage was shown at the 2nd annual meeting of the National Institute on Drug Abuse Clinical Trials Network's (NIDA-CTN) Appalachian Node on February 25th, 2021.

I chose to do this work after my own experiences with seeking diagnosis and treatment for another highly stigmatized condition - in my case, borderline personality disorder (BPD). One of the diagnostic criteria I fulfill for that condition is impulsive substance use. I have a personal history of binge drinking to self-medicate, with an extensive family history of alcoholism. The complexity of my issues left me bouncing from doctor to doctor without making any ground for most of my adolescence. It was not until I had a collaborative mental health team that I actually started making progress in multiple areas of my life, versus tackling single issues and continuously relapsing. Armed with knowledge from my medical past, I wanted to dig deeper and look at how collaboration benefits patients and communities, and what the greatest barriers may be standing in their way.

Growing up in a small Wisconsin town, I was largely ignorant of Appalachian life until I relocated two years back to pursue my graduate degree at West Virginia University. When I first started looking into substance use disorders-inside the state, I turned to national news outlets, and then moved onto more Appalachia-focused research. Prior to this project, most of what I knew 
about substance use in the Mountain State came from sensationalized news articles. Throughout the process, I began to notice how easy it was to find dramatic imagery and shocking statistics, such as the overdose death rate in West Virginia being 51.5 per $100 \mathrm{k}$ vs the national rate of 20.7 per 100k, while being difficult to find stories that centered around progress and celebration of achievements, like the many stories I heard from the people I interviewed ("2018 drug overdose death rates", 2021). Of course, I am not advocating for hiding the truth to spare feelings - I think the shocking statistics are just as important as the more hopeful statistics. But I began to wonder the effect lack of hope could have on collaboration efforts, and how stigma may be an overarching barrier. This idea later became another part of what I explored through the interviews.

The main question I was hoping to answer was the power collaboration has when it comes to complex issues like substance use disorders. What are ways people can work together to create change? How can people get involved in this area of research, whether they are researchers or clinicians themselves, or just a random community member who is tired of watching people suffer? I anticipated hearing about brick-and-mortar resources, raising awareness for programs, different volunteer opportunities, and other clearly treatment-related options. The overwhelming response was far simpler - better communication. Whether it was a need for listening more closely, communicating more concisely, or speaking out against stigma, the overall consensus was that we as a society need to work on how we talk to each other about substance use. 


\section{The Project}

\section{Project Description}

The project consists of this paper and a short film providing a look into substance use disorder research collaboration at West Virginia University. Footage used in the short film was pulled from a series of interviews with 14 researchers from various professional backgrounds who all work in an aspect of substance use disorder. The film portion of the project is approximately 14 minutes in length.

\section{Implications}

This project was shown on February 25th, 2021 at the annual meeting of the Clinical Trials Network's Appalachian Node. Going forward, it can be utilized on the Appalachian Node's website and presented at other conferences to introduce researchers to other potential collaborators. It can also be an informative piece for the general public and can aid in fighting one of the biggest obstacles in treatment of substance use disorders: stigma. The overall purpose of the project is to connect researchers and educate viewers on the current status of the opioid epidemic in rural environments. The majority of the people involved in the project expressed interest in working together again in the future, leaving the door open for further exploration and future multimedia projects.

\section{The Process}

Video production had particular complications as interviews took place during a pandemic. COVID restrictions made it unwise to hold in-person interviews, so footage was instead recorded from Zoom video call interviews. The project had a quick turnaround, with interviews taking place in January 2021 and the majority of the data organization and editing 
happening in February. The overall process had seven stages - 1) Establishing Research Statement and Methodology 2) Identifying Subject Pool, 3) Scheduling, 4) Conducting Interviews, 5) Organizing Footage and Transcripts, 6) Video Production and 7) Meeting Presentation. Across those stages, I engaged in 18 different steps before completing the project.

\section{Establishing Research Statement and Methodology}

Step 1) Research Statement and Methodology: Research collaboration efforts like those of the Appalachian Node give the opportunity for a more well-rounded understanding of substance use disorder. This project discusses current research collaboration efforts in addition to exploring how community members can contribute to collaboration and what barriers may be slowing progress.

In addition to the interviews, I drew upon a variety of sources to inform this project, including: grant applications, news articles, research published by the interviewees, and related research. I entered this project knowing the researchers are not people who get voice in media very often and they may have different perspectives from what is commonly seen online - I avoided recognizably biased literature, to the best of my ability, until after conducting the interviews.

I used a combination of narrative analysis and content analysis methods in this project. By analyzing the stories told in the interviews and comparing them to information available in relevant articles and assorted media, a second research focus on media contributions to SUD stigma arose.

\section{Identifying Subject Pool}

Step 2) Identify subjects: Guided by Dr. Judith Feinberg, the Co-PI for the NIDACTN Appalachian Node, I identified 13 West Virginia University researchers and 
clinicians and one community partner all whose work focuses on some aspect of substance use disorders. When available, I relied on researchers" "biosketches" to get first knowledge of their work. A biosketch is a document typically required of National Institute of Health grant applicants, which serve to "demonstrate the magnitude and significance of scientific advances associated with their discoveries, and the specific role they played in those findings" (FOGARTY International Center @ NIH, n.d.). They were incredible documents to have access to as they gave me an opportunity to see each researcher write about their work in their own words, almost like a pre-interview. For the ones I did not have a biosketch for, I did some extra digging for articles they have written or news stories about their work.

The complete list of interviewees was as follows:

- Alfgeir Kristjansson, $\mathrm{PhD}$ - Associate Professor of Social and Behavioral Sciences, WVU School of Public Health. Primary research: primary prevention of drug use for children and youth.

- Brian Hendricks, PhD - Research Assistant Professor of Epidemiology and Biostatistics, WVU School of Public Health. Primary research: spatial epidemiology, application of geographic information systems and spatial analyses to identify geographic variations

- Erin Winstanley, PhD - Associate Professor of Behavioral Medicine and Psychiatry, WVU School of Medicine. Primary research: expertise in preventing overdose-related morbidity and mortality.

- Gordon Smith, MD - Stuart M. and Joyce N. Robbins Distinguished Professor of Epidemiology and Biostatistics, School of Public Health. Adjunct Professor of 
Emergency Medicine, WVU School of Medicine. Primary research: overdose, improving data systems for substance abuse, and substance abuse problems in rural areas.

- James Mahoney III, PhD - Assistant Professor of Neuroscience, Behavioral Medicine \& Psychiatry, WVU School of Medicine. Primary research: neuropsychosocial and cognitive changes due to substance use, neuromodulation as adjunctive treatment for substance use disorder.

- Judith Feinberg, MD - Vice Chair of Medicine for Research, Professor of Medicine/Infectious Diseases, and Professor of Behavioral Medicine and Psychiatry, WVU School of Medicine. Primary research: expertise in the infectious and social complications of drug use.

- Kelly Lemon - Certified Nurse Midwife and Instructor of Obstetrics and Gynecology, WVU School of Medicine. Primary research: substance use in pregnancy.

- Laura Lander - Associate Professor of Neuroscience, Behavioral Medicine and Psychiatry, WVU School of Medicine. Primary research: behavioral treatments for substance use disorders and medication for opioid use disorder in pregnancy. - Mark Garofoli, PharmD - Clinical Assistant Professor of Pharmacy, WVU School of Pharmacy. Primary research: Prescription opioids and substances of abuse.

- Steve Davis, PhD - Associate Professor of Health Policy, Management and Leadership, WVU School of Public Health. Primary research: "implementation and dissemination of evidence-based technologies and programs (e.g. telehealth, 
needle exchange, medications for opioid use disorder, etc.) in rural communities" (“Steve Davis", 2020).

- Toni Rudisill, PhD - Research Assistant Professor of Epidemiology, WVU

School of Public Health. Primary research: drug consumption and impaired driving and impact of large scale interventions on drug-related outcomes.

- Vincent Setola, PhD - Assistant Professor of Neuroscience, WVU School of Medicine. Primary research: Genetics of substance abuse, reducing addiction liability in prescription opioid use.

- Wanhong Zheng, MD - Associate Professor of Neuroscience, Behavioral Medicine \& Psychiatry. Primary research: psychiatry and addiction medicine.

I also reached out to Laura Jones, the Executive Director of local free health care clinic Milan Puskar Health Right. She developed the first syringe services program in West Virginia and has an expertise in social work with an emphasis in treating people addicted to opioids. Health Right has partnered with WVU Medicine on substance use research, which made Jones relevant for inclusion.

\section{Scheduling}

Step 3) Make introductory emails: After identifying potential subjects, I contacted each person directly to introduce myself and the project. To stay organized throughout the scheduling process, I tracked when I sent and/or received emails from each contact.

Step 4) Send scheduling poll: Interviewees were sent a second email providing more information about the project and inviting them to fill out their availability over a two-week period on a WhenIsGood scheduling poll. 
Step 5) Confirm interview: I followed up with each individual to confirm an interview time based on their poll results.

Step 6) Send questions and link: Approximately 24 hours before each interview, I sent interviewees a list of questions - both general and pertaining directly to their research - and a link to our scheduled Zoom meeting.

\section{Conducting Interviews}

Step 7) Pre-interview setup and troubleshooting: Each interview started with introductions and adjustments to technical setups. For most of the interviewees, this was a 2-3 minute process wherein I instructed them where to reposition themselves, their cameras or their lighting if needed. For some, we had to dedicate a portion of the interview time to trying to troubleshoot problems including bad lighting (Dr. Steve Davis, Laura Jones and Dr. James Mahoney), unsatisfactory but stationary/immovable camera setups (Dr. Wanhong Zheng and Dr. Brian Hendricks), and low quality audio with no immediate microphone alternatives (Dr. Steve Davis). Also of note, Dr. Vincent Setola declined to be on camera the day of the interview and gave an audio-only interview.

Step 8) Conduct interviews: During the interviews I used a small list of general questions about collaborative research in rural Appalachia and community involvement, while asking interviewees specific questions about how their work relates back to the general ideas at hand. Interviews were scheduled for 20-30 minutes each; most ran to 45 or 60 minutes as their passion for their work led to enthusiastic discussion.

\section{Organizing Footage and Transcripts}

Step 9) Auto-transcriptions: Following the interviews, I fed the footage into an autotranscription software program called Otter.ai. 
Step 10) Correct auto-transcription errors: After auto-transcription I was left with 300 pages of interview transcripts which I combed through for corrections.

Step 11) Index transcripts: I then indexed my transcripts, starting with writing general subjects of conversation in the margins of each page.

Step 12) Identify common themes: I made a document per each person listing all of the topics discussed in their interview, with page numbers. From that document, I started to identify the most common themes - "Collaboration," "Medical terms/models," "Stigma/barriers," "Rural vs urban," "Syndemics," "Hopes for the future," and "Other."

Step 13) Create a master list of quotes organized by theme: I created an Excel spreadsheet to serve as a master list to organize useful quotes by topic. Under each heading I notated quotes in a "(Last Name) (Page Number) // (5-15 word summary)" format, e.g. under the heading "Hopes for the future," I have "Winstanley 18 // Storytelling as a way to connect."

Step 14) Identify a storyline: At this point, having become familiar with the content by repeatedly combing through transcripts, I looked for relevant quotes between interviews to find a story flow.

\section{Video Production}

Step 15) Assemble footage: Once I identified a logical order through the transcripts, I began assembling the video footage. The goal was a 30-45 minute documentary with a narrative flow.

Step 16) Project review and overhaul decision: About a week into assembling footage and with the deadline nearing, I showed my committee the first draft. At that point, after taking into consideration the limited time left and work still to be done, it was determined that the project needed to be changed and overhauled in order to meet the deadline. 
Step 17) Project rearranged into short film. The video project was rearranged into a short film with graphics describing the researchers and featured some of their most impactful quotes and stories. Due to the aforementioned technical issues and time constraints, I had to cut content from Dr. Mark Garofoli, Dr. Brian Hendricks, Kelly Lemon, Dr. Vincent Setola and Dr. Wanhong Zheng. The remaining 9 people were all selected based on quality of video footage, variety of research focus, relevance to topics featured in the film, and how clear and concise their quotes were. The final product clocked in 14 minutes and 21 seconds.

\section{Meeting Presentation}

Step 18) I was invited to participate in a the socially-distanced in-person portion of the annual Appalachian Node meeting at the WVU Erickson Alumni Center on February 25th, 2021. Including the approximate 15 people in physical attendance, the conference was streamed live and featured virtual participants. The video was shown, followed by a brief Q\&A discussion with the audienceand myself.

\section{Conclusions}

\section{Technical Aspects}

There were unanticipated challenges in this project as a result of utilizing Zoom footage a necessary, safe format for conducting interviews during a pandemic. Having never conducted Zoom interviews before, I did not have experience in troubleshooting common issues and had to learn as they appeared. The quick turnaround of this project, with interviews taking place in early January and the deadline in late February, meant in most cases I only had one opening to fit into most of the interviewee's schedules. This left little room for error and I had to make judgment calls based on how long it would take to remedy a technical problem - if I felt it was more than a 
10 minute fix, I continued on with the interview with the problem as remedied as possible. An example of this was Dr. Steve Davis's setup, which he lovingly called "The Batcave" and for good reason - it was tucked away in a sunless corner with only one lamp as a light source. He had no alternative location, so my options were either continue with the interview after some adjustments and hope to rescue the footage in post, or cancel the interview altogether.

Another contributing factor to technical issues was also nerves - many of these clinicians and researchers work with people not unlike myself. My personal history with stigma in psychiatric care had my guard up, as I was worried I would be viewed as a patient versus a graduate student. Despite my fears of judgment and knowing the vulnerability surrounding the topic of substance use, I made the personal decision to be open about my own experiences, hoping it would foster trust and openness. It was a beneficial decision and I was met with reciprocal vulnerability and lack of judgment across the board, but the nerves had an influence on my ability to both notice and speak up about some corrections.

When working with virtual video interviews in the future, I would prioritize having enough time to work with the interviewees to find ideal interview locations and fix any equipment-related issues pre-interview. There is strong potential for this project to be expanded and improved upon, especially once in-person interviews are a safe option. Ultimately, keeping in mind the tight deadline, I felt it was to the project's benefit to utilize interviews over Zoom as it meant interviews were less intrusive and could be stacked back-to-back without the need to set up, tear down and transport video equipment.

\section{Insights}

From this experience, I have come to more deeply understand the many ways stigma can act as a barrier to treatment and communication. Concepts like overdose-related compassion 
fatigue help to explain the spread of apathy within communities, and negative, stigmatized perceptions of Appalachia demonstrate why it is difficult to get people outside of the region to care.

It is clear that the medical system needs overhaul. I have experienced the impacts of stigma and the dire need for change through my own treatment journey, which has been complicated by lack of treatment for my substance use-related risk behaviors. In 2016, I attempted suicide through overdosing on prescription opioids and binge drinking. In the days following, none of the professionals treating me - including those in the ER and ICU - dug deeper into my relationship with either substance. The first night I was in the hospital, I was told by a nurse that I was taking up a room that could have been used for someone with "real problems." Two days later, a psychiatrist accused me of doing it all for attention and shamed me to the point where I withdrew voluntary consent to be taken into inpatient psychiatric care and was admitted involuntarily. The stigma I faced and the lack of intervention with my drinking at such a crisis point in my life led to my binge drinking problem escalating in the following months and years. I was very lucky not to form an addiction to opioids. This is one of many times I have been failed by the medical system, and I am only one person.

These researchers and clinicians see it every day. Patients live it. But people whose lives are seemingly untouched by substance use disorder do not have the same perspective. The evolution of the substance use disorder care team to include peer recovery support specialists, or certified individuals who have been through the recovery process, has given people with lived experience a chance to have a greater voice. In his interview, Dr. Steve Davis discussed his work introducing peer recovery support specialists to emergency departments across West Virginia. As a part of this, substance use screening is built into the triage process and peer recovery support 
specialists can be sent in to speak with people who are flagged by the system. Dr. Davis says, "You need hope, and resources that provide hope" (S. Davis, personal communication, January 17, 2021). When positive outcomes are rarely heard about, hope can be hard to find. Peer recovery support specialists show patients that recovery is possible and there are people ready to help them through it whenever they are ready, meeting people where they are instead of shaming them if they are not yet ready for the work of recovery.

Delving into the collaborative research being done on substance use disorder has made me realize that there $i s$ help out there, but it is often overshadowed by misinformation and stigma. A person spending every day hearing stigmatized language about themselves can struggle to feel as if they deserve recovery. Tragically, when the population at large views substance use disorders in a negative light, happy stories about recovery have a limited receptive audience. In the Netflix documentary limited series The Trials of Gabriel Fernandez (2020), Dr. Astrid Heppenstall Heger, Executive Director of the Violence Intervention Program (VIP) at Los Angeles County-USC Medical Center, speaks to the brokenness of the American criminal justice system, saying "I believe the ultimate evil in this world is knowing what's wrong, seeing what's wrong, and looking away." I have to wonder if, when applying this statement to treatment of substance use in mass media, some people look away less out of true apathy and more because they do not actually understand the reality of what they are being shown. When we speak of the faults within systems like medicine or criminal justice, we cannot ignore how news and entertainment media play a hand in how the world reacts. There is a massive opportunity for collaboration within respective fields and systems to reduce stigma and increase empathy. I believe, especially after this project, storytellers have a responsibility to stop and consider the 
ways their media can impact vulnerable populations such as people living with substance use disorders.

\section{Suggestions for Future Research}

The researchers who participated in this project are often unseen forces - showing their work and getting their research out is a part of humanizing the world of SUD research. The breadth of their research cannot be captured in a single film, with much more work to be shown and done. In total, I collected approximately 12 hours of footage in the making of this short film. The unused footage can be utilized for a long-form film or repackaged into features on the researchers. The interviews can also be used as pre-interviews should I pursue in-person interviews to create a more traditional documentary (versus one composed of Zoom interviews) in the future.

The short film can be helpful in collaboration efforts as it can be shared with other researchers to promote the goals of the Appalachian Node, thus connecting people with similar research interests. Outside of research, it can be a method for the everyday citizen to unfiltered scientific information from the researchers themselves. Gathering feedback from viewers on the film's effectiveness in spreading awareness and encouraging collaboration may aid in further development of this genre of SUD film.

My hopes for this project is that it is only the first of many video projects to highlight current research collaboration on substance use disorder in West Virginia, giving viewers the ability to know what is happening in their community, see how they can help, and consider whether or not they are perpetuating stigma. 


\section{Literature Review}

Seeking to understand previous, ongoing and completed work on the topic of ruralfocused research collaboration for substance use disorder, I examined relevant work pertaining to SUD treatment in West Virginia and reviewed the Appalachian Node website to become more familiar with the group. When asking the greater question of "how can people collaborate better?" it is helpful to consider what barriers may be in their way. After discovering the widespread influence of stigma and some of its impacts on communities I delved into research on stigma, which led me to Dr. Erin Winstanley's concept of overdose-related compassion fatigue (OCF). Lastly, I considered various examples of filmic treatments surrounding the topic of substance use and the importance of perspective.

\section{Substance Use Disorder Research Collaboration in West Virginia}

With West Virginia at the heart of the opioid epidemic, the sheer amount of information available about substance use disorder in Appalachia can be overwhelming. Simply Google searching "wvu substance use disorder" returns about 218,000 results - some mentioning the Comprehensive Opioid Addiction Treatment (COAT) program at Chestnut Ridge, the Drug Free Moms and Babies (DFMB) Project, statewide harm reduction efforts such as needle exchanges, implementation of peer recovery support specialists, medications for opioid use disorder, and many more SUD-related topics. Then one has to take into account the unique struggles West Virginians face when it comes to lack of nearby providers, transportation barriers such as the near absence of public transportation in rural areas and the costs of owning and operating a vehicle, low health literacy in rural areas, and limited healthcare resources, especially with regard to SUD treatment. Appalachian culture itself has an influence on health as well, with West Virginians being notably independent (Holdren 2018, Young 2019) and the existence of 
'rural fatalism'. While the national median household income in 2019 was \$68,703, in West Virginia it was only \$53,706 (Statista Research Department 2021); moreover workforce participation is the lowest in the U.S. at only 54\%. Stepping back and looking at all of the factors at play highlights the need for people to approach the overarching issue of substance use disorder from every angle.

When discussing the need for a team approach, the "biopsychosocial model" came up often in both my research and the interviews. Dr. George Engel, the psychiatrist who developed the biopsychosocial model "...to provide a basis for understanding the determinants of disease and arriving at rational treatments and patterns of health care, a medical model must also take into account the patient, the social context in which he lives, and the complementary system devised by society to deal with the disruptive effects of illness, that is, the physician role and the health care system. This requires a biopsychosocial model.” (Engel 2012). The researchers I interviewed for this video represent a broad range of interests, including overdose and related mortality, acute psychiatric care, distracted driving due to drug use, the development of the Icelandic Prevention Model to reduce substance use by teens, use of medications for opioid use disorder in pregnant women, harm reduction efforts including syringe services and education to prevent and recognize opioid overdose and prevent fatalities with the overdose reversal drug naloxone, use of peer recovery support specialists as a way to reach out to and support people who inject drugs (PWID), and much more. In addition, there are a wide range of "syndemics," defined by the Centers for Disease Control as "a term invented to describe a set of linked health problems; two or more afflictions or epidemics interacting simultaneously and synergistically (together having a greater effect than would be expected by adding the effects of each); epidemic synergy contributing to excess burden of disease in a population" (Healthy Places Terminology 
2021). Drug use syndemics include increased rates of HIV and hepatitis C transmission, trauma in children who are removed from their homes and placed into guardianship due to parental drug use, incarceration or death, increased job loss and homelessness, transmission of HIV and hepatitis infection to newborns, and babies born in withdrawal from maternal opioid use among others. Both the biopsychosocial model and the multiple injection drug syndemics are best served by collaborative substance use disorder research.

A key example of the biopsychosocial model in use at West Virginia University is the highly successful Comprehensive Opioid Addiction Treatment (COAT) program. Developed in West Virginia with involvement from a number of individuals interviewed for this project, the COAT program is a novel multi-phase group-based treatment model which utilizes a combination of medications of opioid use disorder (MOUD), regularly scheduled psychosocial group therapy, and a diverse care team to treat patients. It has shown great success in retention among rural patients who typically struggle to access care, in part because the group-based model allows for more patients to be treated by fewer providers (Lander, et al, 2020). Patients benefit from the group-based model as, unlike individual therapy, it "specifically assists with the development of interpersonal connections, provides positive social support and pressure to change, decreases stigma, and promotes the development of interpersonal skills as well as the practice of those skills in vivo" (Wendt \& Gone, 2018, pp. 9-17). The success of the COAT Program, also referred to as the "West Virginia model," demonstrates the power of collaboration in reducing healthcare access barriers.

\section{The Appalachian Node of the Clinical Trials Network}

Participation in the National Institute on Drug Abuse Clinical Trials Network (NIDACTN) is one of the many ways research collaborators come together. The NIDA-CTN is built up 
of a series of "nodes" spread across the United States, including our very own aptly-named Appalachian Node. Situated in central Appalachia, this node is made up of collaborators at the University of Pittsburgh, West Virginia University and Penn State University who aim to improve negative health outcomes in rural areas which are disproportionately impacted by substance use. The Appalachian Node has special interest groups, including the Rural Special Interest Group, which focuses directly on issues pertaining to rural residents with and at risk for substance use disorder. Of the people interviewed for this project, three are associated officially with the Appalachian Node. Dr. Feinberg is the Co-PI, and Dr. Erin Winstanley and Laura Lander are listed on the Appalachian Node website under Affiliated Faculty (NIDA-CTN Appalachian Node, n.d.).

On their website, the Appalachian Node is described as a "team of accomplished clinical and research collaborators" who "organize and participate in national, community-based multisite trials and subsequently disseminate research findings to physicians, clinicians, providers and patients" (NIDA-CTN Appalachian Node, n.d.). While the video's purpose was to be shown at the annual Appalachian Node meeting, it was important to include potential collaborators to facilitate new joint research efforts.

\section{Overdose-Related Compassion Fatigue and Stigma}

This project started with the word collaboration in mind, but as interviews went on another equally important word started to rear its head - stigma. When proposing this project, I brought up Chattoo \& Das (2014) who described the path to effective impact as “...paved by identifying the kind of change a story hopes to encourage, from individual change (knowledge, attitudes, behaviors) to public interest change (legislation, policy) to institutional change (corporate, systems)." I wanted to get an idea of what change is most needed from people who 
have absolutely immersed themselves in this area of research. So in each interview I asked, "What is one thing you wished people knew more about or supported more that would help with substance use disorder treatment?” I expected to be told about certain community resources, discuss volunteer options, maybe learn about a new kind of treatment, et cetera. But without fail, every single interviewee at some point mentioned stigma as something they wished people were more aware of.

With stigma emerging as an overarching theme, I needed to get an understanding of what stigma means in an academic sense. I quickly discovered that stigma is split into "public stigma" and "self-stigma," both of which can have significant impacts on help-seeking attitudes (Pattyn, et al., 2014). I came across an article that identifies three main "constructs" of public stigma stereotypes, prejudice and discrimination. They are defined, respectively, as "overgeneralized, typically disrespectful beliefs about a group," "agreement with the stereotypes that leads to emotional reaction," and "unfair behavior directed towards the individual or group" (Nieweglowski, et al., 2018). With these definitions in mind, I was able to better identify the impact of stigma related to substance use disorder.

In the video, Dr. Erin Winstanley speaks about overdose-related compassion fatigue (OCF), a term she coined which can be described as "...distress resulting from knowledge of or exposure to overdose-related harms, which at the community level may prohibit collaboration and adaptive agency to effectively respond." (Winstanley, 2020). If people are barraged constantly with negative imagery and stereotypes, they become desensitized and show less empathy out of self-preservation - “...when OCF occurs at a community level, it could have negative consequences by eroding support for evidence-based services and fueling stigma-driven policies that blame people who use drugs" (Winstanley, 2020). The concept of OCF is an 
integral part of understanding attitudes toward substance use in rural Appalachia, where people are suffering at disproportionate levels due to the emotional toll of repeatedly losing members of their tight-knit rural communities. The use of stigmatized language when trying to reach communities plagued by OCF can fuel an already raging fire toward further misunderstanding and harm. I took this into account while editing and made sure to use more informative quotes in the video rather than purely emotional statements.

The majority of interviewees expressed a wish for media that would highlight victories instead of falling into the usual sensationalization which can contribute to stigmatization and the spreading of false information. Laura Jones, Executive Director for Milan Puskar Health Right said, 'It's that negativity that keeps the stigma going. But if you are telling a story about how a bunch of people who are probably using substances got together and did karaoke and had an absolutely wonderful time, and no one got hurt, and there were no fights, and everyone was safe... that really happens, you know?” (L. Jones, personal communication, January 26, 2021). Showing positive healthcare outcomes for people in treatment for SUD can contribute to less emotional burnout and more empathy. This can be helpful with OCF: "Empathy underlies both OCF and vicarious resilience by allowing one to understand the suffering caused by overdose deaths and witness the joy of addiction recovery" (Winstanley 2020). Further research on OCF and its relation to increased stigma in rural areas is still in development.

Stigma and lack of education surrounding substance use disorders is rampant on the internet and is so prevalent in our communities that West Virginians are still supporting legislation to ban needle exchange programs in 2021 despite considerable research showing their benefits (Davis, et al., 2018; Phillips, et al., 2018). On April 15th, 2021 the Associated Press reported that West Virginia Governor Jim Justice signed a bill that will introduce “...more 
stringent requirements to needle exchange programs that critics say will make it harder to get clean needles amid a spike in HIV cases in the state.” (Raby, 2021). The increase in HIV among PWID in the state after the needle exchange closure in Charleston in 2018 has led to increased demonization of substance use. Dr. Feinberg has acknowledged that the shortsighted focus on opioids has kept us from tackling changes in substance use: "The narrow focus on opioids means we cannot keep up with the drug du jour cycle: we will just keep playing whack-a-mole.” (Feinberg, 2019). It is evident from speaking with these researchers and clinicians that, in addition to compassion fatigue, many stigma-related problems stem from misunderstanding substance use disorder as a moral failure rather than the chronic, relapsing brain disease that it is. The use of video can be helpful with barriers to understanding the nature of substance use disorder as a disease, but the manner in which one accomplishes this has to be careful not to contribute to existing stigma. The A\&E reality show Intervention (2005) has caused controversy over its 22 seasons due to its sensationalized portrayal of people in active addiction. Claims have been made that it “...sensationalizes the lowest moments of a person's life for TV ratings" (Whelan, 2019). The bait-and-switch premise of the show itself, where participants are told they are being featured in a documentary about addiction and then are later blindsided with a carefully staged intervention, is in direct conflict with the public health practice of harm reduction and the idea of meeting people where they are.

In an interview with the Philadelphia Inquirer, Temple University Professor Jillian BauerReese, who teachers a journalism class on addiction, commented on the careful balance of showing sensitive topics like addiction: "It comes back to the balance between what the public needs to know, and whether what you're showing them is causing harm to the people that you're, essentially, using as a symbol for a social issue" (Whelan). 
An example of a more well-rounded, transparent media piece is the short documentary film Heroin(e) (2017) which follows three women - Fire Chief Jan Rader, Cabell County Judge Patricia Keller, and Necia Freeman of the Brown Bag Ministry - as they fight the opioid epidemic on multiple fronts in Huntington, West Virginia. Viewers are educated on the use of naloxone, learn about psychological impacts on first responders, witness authentic drug court proceedings, and get familiar with a number of people in various stages of recovery over the course of dozens of interviews. The film was created with an intentional awareness of stigma. Filmmaker Elaine McMillion Sheldon expressed hopes that the film can “...help destigmatize addiction so that the nation can begin to treat the opioid problem as a public health crisis, rather than a 'moral failure' of those suffering from addiction." (Mitchell, 2018) Through the interview process, the idea of addiction as a health crisis versus a moral failing kept rearing its head as a major stigma-related barrier to progress. Mindfulness of that dichotomy of public opinion and science can lead to more sensitive, less harmful media content.

Returning to Chattoo \& Das' concept of the path to effective impact and applying it to what I have come to understand throughout this process, I now recognize that stigma is a roadblock in all three spheres associated with effective impact - individual, public interest and institutional change. One cannot change public interest or institutions without first connecting with the individuals at the helm. When asked about differences between rural and urban research and how they can help each other, Dr. Mark Garofoli noted. "It's one at a time, folks. And research within a rural setting, like the many efforts here in West Virginia, can help with that. To bring down the big bubbles, and say that no matter what, it's still going to be one at a time. Because even if you're doing something for 1,000 people at once, you're going to have to have a one-on-one along the way, because it's going to be one mind changing along the way." (M. 
Garofoli, personal communication, January 15, 2021) Considering that public interest and institutional change rely on the individual beliefs and knowledge of each person involved, I think there is a lot of room to look into how heavily a singular person's stigma can permeate the world around them, and how the furthering of stigma in media can be a roadblock to progress and collaboration.

\section{Filmic Treatments}

The topic of addiction and recovery has been covered in many forms from varying perspectives - families, law enforcement, healthcare professionals, government, and people who use drugs themselves. Eponymous celebrity accounts such as YouTube docuseries Demi Lovato: Dancing with the Devil (2021) and BBC documentary Russell Brand: From Addiction to Recovery (2012) are often helpful in drumming up conversation and sympathy. In the previous section, I mention both Heroin(e) (2017) and Intervention (2005) and the way they differ in perspective and format. I particularly enjoyed Heroin(e)'s cinéma vérité approach as it provided viewers with a very raw perspective of life in Huntington, West Virginia. Professionals presented facts, sensitive topics were handled tactfully and the film explored multiple viewpoints, including those of first responders, community leaders, the judicial system, and people in both recovery and active addiction.

The level of sensitivity shown in the films above is not always present in other media surrounding this topic. While Intervention does capture the whole intervention process, the premise of the show itself is more focused on the loved ones of the family and their desire for the intervention - to the point of being accused of being exploitative. There is also the stigmatized portrayal of drug use in reality shows centered on drug dealers and law enforcement, such as A\&E docuseries 60 Days In (2016) and Fox's 33-season television series Cops (1989). These 
shows often portray persons with substance use disorders in a one-sided manner from the perspective of law enforcement. Counter to these portrayals, there are other cinéma vérité films about drug addiction that hone in on the perspective of persons with SUD themselves, such as Heroin: Cape Cod (2015) and Recovery Boys (2018).

What appears to be most common of all are documentaries educating people about the opioid crisis and its impacts on communities from many angles. Examples of these include Addicted: America's Opioid Crisis (2019), Understanding the Opioid Epidemic (2018) and HBO's Addiction (2007) series. However, none of these focus on the collaborative research work being done behind the scenes. My project seeks to fill a gap and contribute to perspective on how community members can collaborate with each other, people with SUDs, and researchers and clinicians. Drawing from the interviews, it would appear we need to direct an overwhelming majority of community focus to social support, education and destigmatization. By showcasing the many collaborative efforts in progress in West Virginia, discussing roadblocks, calling attention to problematic language, and having these SUD researchers and clinicians able to deliver their findings directly to the viewer in an accessible format, one is able to present scientific information that challenges stigma. Upon reflection, I believe further work would benefit greatly from including interviews with peer recovery support specialists, as their perspective as people with the lived experience of SUD who are now in sustained recovery is important to having a well-rounded perspective. 


\section{Works Cited}

2018 drug overdose death rates. (2021, March 22). Retrieved April 22, 2021, from https://www.cdc.gov/drugoverdose/data/statedeaths/drug-overdose-death-2018.html

Alpert, J., Berlinger, J., Davis, K., Garbus, L., Hegedus, C., Jarecki, E., Kopple, B., Maysles, A., Pennebaker, D.A., Raymond, S., Sinofsky, B. (Directors). (2007). Addiction [Film]. HBO.

Chattoo, C, Das, A (2014) Assessing the social impact of issues-focused documentaries: Research methods and future considerations. Center for Media and Social Impact. Available at: http://www.cmsimpact.org/sites/default/files/documents/ assessing_impact_social_issue_documentaries_cmsi.pdf (accessed 20 March 2015).

Conway, D. (Director). (2019). Addicted: America's Opioid Crisis [Film]. BBC Three.

Davis, S. M., Davidov, D., Kristjansson, A. L., Zullig, K., Baus, A., \& Fisher, M. (2018). Qualitative case study of needle exchange programs in the Central Appalachian region of the United States. PloS one, 13(10), e0205466. https://doi.org/10.1371/journal.pone.0205466

Engel, G. L. (2012). The Need for a New Medical Model: A Challenge for Biomedicine. Psychodynamic Psychiatry,40(3), 377-396, 386.

Feinberg, J. (2019). Tackle the epidemic, not the opioids. Nature, 573(7773), 165-165. doi:10.1038/d41586-019-02671-9 
“Gabriel's Voice.” The Trials of Gabriel Fernandez, season 1, episode 6, Netflix, 26 Feb. 2020. Netflix. https://www.netflix.com/title/80220207

Grant, J. (Writer \& Producer). (2018). Understanding the Opioid Epidemic [Film]. WNED-TV Buffalo-Toronto.

Henry, G., Woodlard, K., \& Grogan, J. (Executive Producers). (2016). 60 Days In [Television docuseries]. A\&E.

Holdren, W. (2018, October 21). Barriers to rural health care go beyond transportation. Retrieved April 20, 2021, from https://www.register-herald.com/news/barriers-to-rural-health-care-go-beyondtransportation/article_629c4e5e-87bf-5772-a9f6-069449f9f2f6.html

Lander, L. R., Zheng, W., Hustead, J. D., Mahoney, J. J., Berry, J. H., Marshalek, P., \& Winstanley, E. L. (2020). Long-term treatment retention in West virginia's Comprehensive Opioid Addiction Treatment (COAT) program. Journal of the Neurological Sciences, 411, 116712. doi:10.1016/j.jns.2020.116712

Langley, J. \& Barbour, M (Executive Producers). (1989). COPS [Television series]. Fox. McMillion Sheldon, E. (Director). (2018). Recovery Boys [Film]. Available from https://www.netflix.com/title/80177782.

Mettler, S., Sharenow, R. (Creators). (2005). Intervention [Television docuseries]. A\&E.

McMillion Sheldon, E. (Director \& Producer) \& Sheldon, K. (Producer). (2017). Heroin(e) [Film]. Available from https://www.netflix.com/title/80192445. 
Mitchell, J. (2018, February 24). Oscar-nominated 'Heroin(e)' tells story of 3 Heroines saving lives. Retrieved April 26, 2021, from https://www.usatoday.com/story/life/movies/2018/02/23/oscarnominated-heroin-e-tells-story-3-heroines-saving-lives/369488002/

Nieweglowski, K., Dubke, R., Mulfinger, N., Sheehan, L., \& Corrigan, P. W. (2018). Understanding the factor structure of the public stigma of substance use disorder. Addiction Research \& Theory, 27(2), 156-161. doi:10.1080/16066359.2018.1474205

NIDA-CTN Appalachian Node: University of Pittsburgh. (n.d.). Retrieved April 15, 2021, from https://www.ctn.pitt.edu/

NIH public access policy \& Biosketch: What is an NIH Biosketch? (n.d.). Retrieved April 15, 2021, from https://mdanderson.libguides.com/nihaccesspolicy/biosketch

Okazaki, S. (Director). (2015). Heroin: Cape Cod [Film]. HBO Documentaries.

Phillips, M. J., Coustasse, A., Johnson, S., Washington, B. (2018, April). The effectiveness of needle exchange programs in the United States and West Virginia. Slide presentation at the Marshall University Lewis College of Business Research Day, Huntington, WV.

Raby, J. (2021, April 15). West Virginia GOV signs needle exchange Program regulations. Retrieved April 17, 2021, from https://apnews.com/article/legislature-legislation-west-virginia-charleston-c26f19aca070b $88 \mathrm{f} 8 \mathrm{e} 5 \mathrm{f} 95 \mathrm{fd} 59 \mathrm{c} 01 \mathrm{aaf}$

Ratner, M. (Director). (2021). Demi Lovato: Dancing with the Devil [Television Docuseries]. SB Films \& OBB Pictures. 
Statista Research Department. (2021, January 20). Median household income in West Virginia 2019. Retrieved April 18, 2021, from https://www.statista.com/statistics/206036/median-household-income-in-west-virginia/

Steve Davis. (2020, October 22). Retrieved April 15, 2021, from https://theconversation.com/profiles/steve-davis-1164086

Wendt, D. C., \& Gone, J. P. (2018). Complexities with group therapy facilitation in substance use disorder specialty treatment settings. Journal of Substance Abuse Treatment, 88, 9-17. doi:10.1016/j.jsat.2018.02.002

Wilson, R. (Director). (2012). Russell Brand: From Addiction to Recovery [Film]. BBC.

Winstanley E. L. (2020). The Bell Tolls for Thee \& Thine: Compassion Fatigue \& the Overdose Epidemic. The International journal on drug policy, 85, 102796. https://doi.org/10.1016/j.drugpo.2020.102796

Young, C. (2019, November 17). Health care in WV: State faces unique set of CHALLENGES, opportunities. Retrieved April 19, 2021, from https://www.wvnews.com/news/wvnews/health-care-in-wv-state-faces-uniqueset-of-challenges-opportunities/article 18a140c9-7fe0-5ac7-8fd4-56b8700

\section{Ea414.html}

